Original

\title{
Simple Identification of Some Bacillus Species and Related Genera in Food by RAPD Analysis Combined with Morphological Observation
}

\author{
TAKAHISA MIYAMOTO ${ }^{1 *}$, MOTOKAZU NAKAYAMA ${ }^{2}$, CHIE SASAKI $^{1}$, \\ KIYOKO SADAKARI ${ }^{1}$, YUKA ITOH ${ }^{1}$, AKIHITO FUJIMOTO ${ }^{2}$, \\ KEN-ICHI HONJOH ${ }^{1}$ AND MASAYOSHI IIO ${ }^{1}$ \\ 'Department of Bioscience and Biotechnology, Faculty of Agriculture, Kyushu University, \\ 6-10-1, Hakozaki, Higashi-ku, Fukuoka 812-8581, and ${ }^{2}$ Food Creation \\ Center, Kyowa Hakko Kogyo Co., Ltd., 4041, Ami, Ami-machi, \\ Inashiki-gun, Ibaraki 300-0398, Japan
}

Received 30 August 2004/Accepted 20 January 2005

\begin{abstract}
Template DNA from Brevibacillus brevis, Geobacillus stearothermophilus, Paenibacillus macerans, $P$. polymyxa and 10 species of Bacillus was used with the commercially available RAPD Analysis Primers to generate DNA fragments by PCR. Different RAPD band patterns were generated from the DNA of 14 different Bacillus species and related genera with Primer 1 or 4 . The result suggested that the single use of Primer 1 or 4 is effective for the simple identification of these strains of Bacillus and related genera by the RAPD analysis. By the RAPD analyses of the template DNA prepared from bacterial colonies formed on nutrient agar plates after cultivation at $35^{\circ} \mathrm{C}$ for 24 to $48 \mathrm{~h}, B$. brevis, B. circulans, B. firmus, B. licheniformis, $P$. macerans, $P$. polymyxa, $B$. pumilus, $B$. sphaericus, $B$. subtilis and $B$. thuringiensis were identified by the combination of the present RAPD analysis using Primer 4 and morphological observations of colonies, vegetative cells and spores. For identification of $B$. coagulans and $G$. stearothermophilus, the RAPD analyses of the template DNA prepared from colonies formed on standard plate agar after cultivation at $55^{\circ} \mathrm{C}$ for 24 to $48 \mathrm{~h}$ might be effective though further improvements of the assay are required for identification of these Bacillus species. For simple identification of $B$. cereus and B. megaterium by the PCR-based method, the use of other RAPD primers or a specific PCR primer set should be developed in addition to morphological observations of colonies, vegetative cells and spores.
\end{abstract}

Key words : Bacillus/RAPD/Identification.

\section{INTRODUCTION}

The Bacillus species and related genera are of great concern in the food industries since they produce heat resistant spores. Some species such as $B$. anthracis and $B$. cereus are pathogenic to humans and animals (Keim et al., 1997). B. licheniformis, B.

${ }^{*}$ Corresponding author. Tel: +81-92-642-3024, Fax : + 81-92-642-3024. subtilis, and B. pumilus comprise the subtilis group. The relevance of the subtilis group as food poisoning organisms has been recognized recently (Turnbull, 1997). Other species such as B. coagulans and Geobacillus stearothermophilus are of major concern in food production, where they can cause problems in production lines because they are resistant to thermal treatments (Blake and Weimer, 1997). Furthermore, $G$. stearothermophilus causes the flat, sour type spoilage of canned milk coffee. B. subtilis and $B$. 
licheniformis are also frequently isolated from various canned foods. In order to optimize the condition of thermal sterilization of processed foods, it is necessary to clarify the target Bacillus species. Recently, the Bacillus species have been grouped into five distinct clusters according to the phylogenetic heterogeneity of the Bacillus genus based on 16S rRNA gene sequences (Ash et al., 1991). Such phylogenetic studies have led to the creation of new Bacillusderived genera: Alicyclobacillus (Wisotzkey et al., 1992), Paenibacillus (Ash et al., 1993), Virgibacillus (Heyndrickx et al., 1998), Gracilibacillus and Salibacillus (Wain $\phi$ et al., 1999) and Geobacillus (Nazina et al., 2001).

In the traditional approaches to identify a strain of the genus Bacillus, several complicated physiological tests are required. To reduce the labor and time required for their identification, a kit for identification of Bacillus (Berkley et al., 1984) and a random amplified polymorphic DNA (RAPD) fingerprinting assay (Ronimus et al., 1997) have been reported. Ronimus et al. (1997) have reported that the primer with DNA sequence 5'-GGACGACAAG-3' was the most suitable for the identification of the Bacillus species by RAPD assay among 20 primers tested. The first report of the RAPD procedure by Williams et al. (1990) showed how it could be used to identify molecular markers linked to genes of specific interest and discussed the possibility of using this technique to identify genotypes or plant varieties. The RAPD analysis has been applied to the identification and detection of bacteria such as Listeria (Mazurier and Werners, 1992), Lactobacillus (Du Plessis and Dicks, 1995) and Salmonella (Miyamoto et al., 1998). Some primers for the RAPD analysis of pathogenic E. coli are commercially available (Poulsen and Jensen, 1991)

In this study we tested six different commercially available oligonucleotide primers for the simple identification of some Bacillus species and related genera by RAPD analysis. The Bacillus species and related genera isolated from food samples and identified by using the commercially available biochemical screening kit were analyzed by the present RAPD analysis using the selected primer combined with morphological observation of colonies, vegetative cells and spores.

\section{MATERIALS AND METHODS}

\section{Strains}

Brevibacillus brevis IFO 3331, Bacillus coagulans IFO $12583^{\top}$, Geobacillus stearothermophilus IFO $12550^{\top}$, B. thuringiensis IFO 3951, B. thuringiensis IFO 13865 and B. thuringiensis IFO 13866 were obtained from the Institute for Fermentation, Osaka (Osaka, Japan). B. cereus JCM 2152 ${ }^{\top}$, B. circulans JCM 2504 ${ }^{\top}$, B. firmus JCM $2512^{\top}$, B. licheniformis $\mathrm{JCM} 2505^{\top}$, B. megaterium JCM $2506^{\top}$, B. pumilus $\mathrm{JCM} 2508^{\top}$, B. sphaericus JCM 2502 ${ }^{\top}$, B. subtilis $\mathrm{JCM} 1465^{\top}$, Paenibacillus macerans JCM $2500^{\top}$ and P. polymyxa JCM $2507^{\top}$ were purchased from the Japan Collection of Microorganisms (Wako, Saitama, Japan). Bacillus circulans NBRC 13627, $B$. coagulans NBRC 3557, B. coagulans NBRC 3886, $B$. coagulans NBRC 12714, B. firmus NBRC 3330, $B$. megaterium NBRC 12068, $B$. megaterium NBRC 13498 , B. sphaericus NBRC 3525, B. sphaericus NBRC 3527, $P$. macerans NBRC 3490, $P$. macerans NBRC 15041, $P$. polymyxa NBRC 3020 and $P$. polymyxa NBRC 13003 were purchased from NITE Biological Resource Center, Biotechnology Center, National Institute of Technology and Evaluation, Chiba, Japan. B. thuringiensis $\mathrm{B}$ and $B$. thuringiensis sotto were the stock culture strains of our laboratory.

For RAPD analyses of strains of Bacillus and the related genera, which were isolated from chicken soup stock and identified by using the API $50 \mathrm{CHB}$ system (Bio Mérieux S.A., France), the following strains were used: 9 B. brevis strains; 4 B. cereus strains; $4 B$. licheniformis strains; $6 B$. pumilus strains; 1 B. sphaericus strain; 35 G. stearothermophilus strains; and $2 B$. subtilis strains.

\section{Culture conditions}

Unless otherwise noted, the bacteria were cultured overnight at $37^{\circ} \mathrm{C}$ in Tryptic Soy Broth (TSB) (Difco Co., Ltd., Detroit, Mich, USA) or on Nutrient Agar (Difco Co., Ltd., Detroit, Mich, USA). B. coagulans and $G$. stearotheromophilus were cultured at $50^{\circ}$ and $60^{\circ} \mathrm{C}$, respectively, for preparation of genomic DNA.

\section{Primers}

The RAPD Analysis Primers (Amersham Biosciences UK Limited, Amersham, UK) used for RAPD analysis are listed in Table 1.

TABLE 1. The nucleotide sequences of RAPD Analysis Primers

\begin{tabular}{cc}
\hline Primers & Nucleotide sequences \\
\hline 1 & 5'-GGTGCGGGAA-3' \\
2 & 5'-GTTTCGCTCC-3' \\
3 & 5'-GTAGACCCGT-3' \\
4 & 5'-AAGAGCCCGT-3' \\
5 & 5'-AACGCGCAAC-3' \\
6 & 5'-CCCGTCAGCA-3' \\
\hline
\end{tabular}




\section{Preparation of genomic DNA}

Genomic DNA was extracted from bacterial cells by using DNeasy Tissue kit (Quiagen K. K., Tokyo, Japan). The DNA was dissolved in $10 \mathrm{mM}$ Tris- $\mathrm{HCl}$ buffer, pH 8.0, containing $1 \mathrm{mM}$ EDTA (TE buffer).

\section{PCR conditions}

Polymerase chain reaction (PCR) was performed in a PCR Express (Hybaid Limited, Ashford, Middlesex, UK). For RAPD analysis using the RAPD Analysis Primers, PCR reaction was carried out in a $50 \mu$ I-mixture containing $10 \mathrm{mM}$ Tris- $\mathrm{HCl}$ (pH8.8), $50 \mathrm{mM} \mathrm{KCl}, 1.5 \mathrm{mM} \mathrm{MgCl}_{2}, 200 \mu \mathrm{M}$ of each of dATP, dTTP, dCTP and dGTP, 40pmole of the primer, 20ng of template DNA, and $1.5 \mathrm{U}$ of Super Taq DNA polymerase (Sawady technology Inc., Tokyo, Japan). The reaction solution was overlaid with an equal volume of mineral oil and 45 cycles of amplification were done with an amplification cycle constituted of template DNA denaturation at $95^{\circ} \mathrm{C}$ for $30 \mathrm{sec}$, primertemplate annealing at $40^{\circ} \mathrm{C}$ for $30 \mathrm{sec}$ and primer extension at $65^{\circ} \mathrm{C}$ for $45 \mathrm{sec}$.

\section{Detection of amplified DNA}

An aliquot $(10 \mu \mathrm{l})$ of the PCR reaction mixture was analyzed by gel electrophoresis in a $2 \%$ agarose gel and $40 \mathrm{mM}$ Tris-acetate buffer ( $\mathrm{pH} 3.0$ ) containing $1 \mathrm{mM}$ EDTA at $3 \mathrm{~V} / \mathrm{cm}$ for $45 \mathrm{~min}$. The gel was stained in ethidium bromide solution $(10 \mu \mathrm{g} / \mathrm{ml})$ and visualized with an UV transilluminator. The $\lambda$ DNA-Hind III digest and 100bp DNA ladder (New England Biolabs, USA) were used for estimation of the size of PCR products.

\section{Morphological observations}

After cultivation of isolates and type strains of each Bacillus species and the related genera on Nutrient agar (Difco Co., Ltd., Detroit, Mich, USA) at a suitable temperature for 24 to $48 \mathrm{~h}$, colonies were observed through a Nikon Stereoscopic microscope SMZ-2T (Nikon, Japan). These colonies were picked up and suspended in water and the vegetative cells and spores were observed through a Nikon Optiphoto phase contrast microscope at $1000 \times$ magnification.

\section{RESULTS}

\section{DNA band patterns generated by using RAPD Analysis Primers}

Template DNA from $B$. brevis, $P$. macerans, $P$. polymyxa, G. stearothermophilus and 10 species of Bacillus were used with the RAPD Analysis Primers to generate DNA fragments by PCR. Among the 14 species tested, 11 strains were type strains. Figure 1
(A) Primer 1

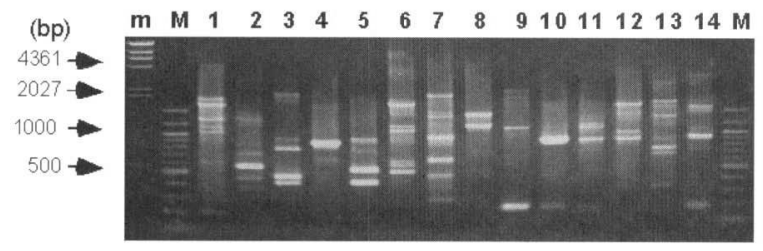

(B) Primer 2

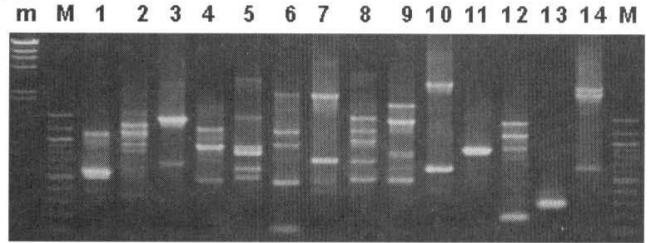

(C) Primer 3

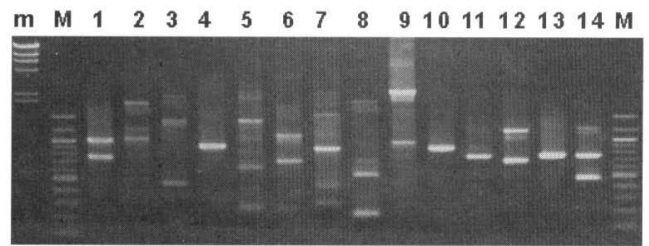

(D) Primer 4

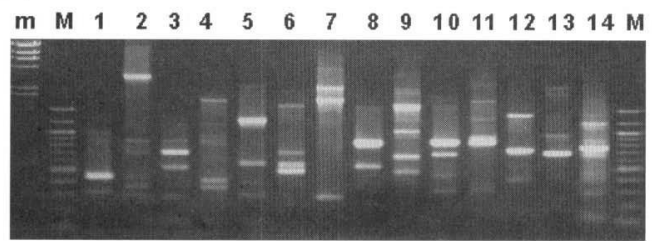

(E) Primer 5

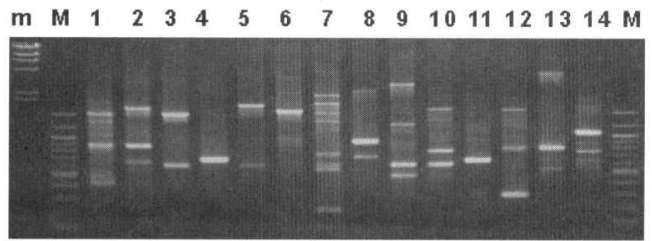

(F) Primer 6

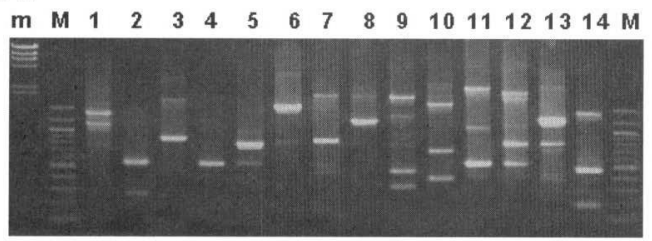

FIG. 1. The DNA band patterns generated with RAPD primers and genomic DNA from some Bacillus species and related genera. The commercially available RAPD Analysis Primers 1 to 6 were used for the RAPD analysis and the RAPD band patterns were shown in $(A)$ to $(F)$, respectively. Lanes: $m, \lambda$ DNA-Hind III digest; $M, 100$ bp DNA ladder; 1, B. brevis IFO 3331; 2, B. cereus JCM 2152'; 3, B. circulans JCM 2504 ${ }^{\top}$; 4, B. coagulans IFO 12583'; 5, B. firmus JCM 2512 ; 6, B. licheniformis JCM 2505'; 7, P. macerans JCM 2500 $; 8$, B. megaterium JCM 2506 $; 9$, $P$. polymyxa JCM 2507'; 10, B. pumilus JCM 2508'; 11, B. sphaericus JCM 2502 ${ }^{\top} ; 12$, G. stearothermophilus IFO $12550^{\top} ; 13$, B. subtilis JCM $1465^{\top} ; 14$, B. thuringiensis B. 
shows RAPD band patterns obtained for these strains after 45 cycles of amplification. The RAPD analysis using Primer 2 generated only 1 band with genomic DNA from B. sphaericus and B. subtilis. These strains also showed the same RAPD band pattern with Primer 3. By the use of Primer 3, the RAPD band patterns were also same in B. coagulans and B. pumilus. Similar RAPD band patterns were generated from the DNA of $B$. licheniformis and $G$. stearothermophilus with the same primer. With Primer 5, the same RAPD band pattern was generated from B.coagulans and $B$. sphaericus. The RAPD band patterns generated with Primer 6 were similar between $B$. circulans and $B$. macerans. Different RAPD band patterns were generated from the DNAs of 14 different Bacillus species and related genera with Primer 1 and 4 . The results suggested that the single use of Primer 1 or 4 may be effective for the simple identification of some Bacillus strains and related genera frequently detected in foods by RAPD analysis. In this study, Primer 4 was used for RAPD analyses of Bacillus and related genera isolated from food samples.

\section{RAPD band patterns generated with Primer 4 from the DNA of some strains including isolates from food.}

Genomic DNA was prepared from some strains of Bacillus and related genera including isolates from foods. Figures 2, 3 and 4 show RAPD band patterns generated from the genomic DNA of some strains with Primer 4.

The 9 strains of $B$. brevis isolated from food generated a predominant band at $450 \mathrm{bp}$, the same band which was generated with $B$. brevis IFO 3331 (Fig. 2A). B. brevis isolates also produced bands at 1200 and $1500 \mathrm{bp}$, which were not produced in B. brevis IFO 3331. It seems that these $B$. brevis strains generate the same RAPD band at $450 \mathrm{bp}$ with Primer 4 . The $4 \mathrm{~B}$. cereus isolates produced the same band pattern by the RAPD analysis with Primer 4 (Fig. 2B). The patterns were slightly different from that of $B$. cereus type strain. B. circulans NBRC 13627 generated the same RAPD band pattern with that of the $B$. circulans type strain, JCM $2504^{\top}$ (Fig. 2C). B. coagulans NBRC 3557 and 12714 generated slightly different RAPD band patterns from that of the type strain JCM $12583^{\top}$ with Primer 4 (Fig. 2D). The RAPD band patterns of NBRC 3886 and the 3 strains isolated from foods were quite different from that of the type strain. B. firmus NBRC 3330 generated the same RAPD band pattern with that of $B$. firmus type strain, JCM 2512 ${ }^{\top}$ (Fig. 2E). Three B. licheniformis isolates produced the same RAPD band patterns (Fig. 3A, Lane 2, 3, and 4). Another B. licheniformis
(A) B. brevis

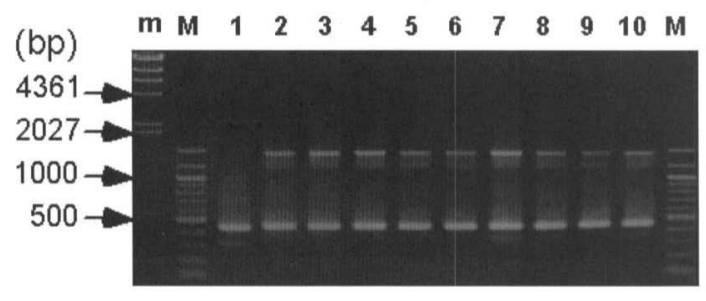

(B) B. cereus

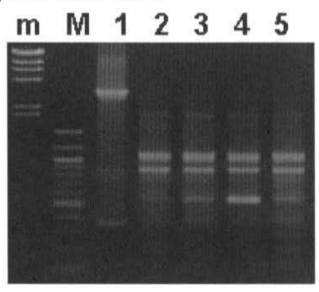

(C) B. circulans

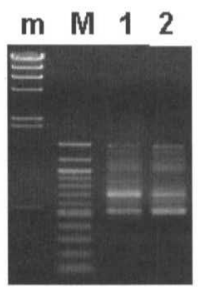

(D) B. coagulans

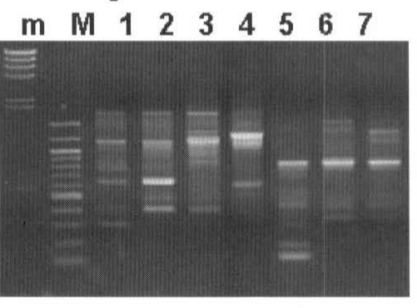

(E) B. firmus

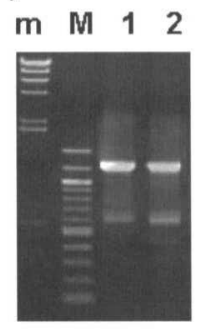

FIG. 2. The DNA band patterns generated with Primer 4 and genomic DNA from some strains of Bacillus and related genera. Lanes: $\mathrm{m}, \lambda$ DNA-Hind III digest; $\mathrm{M}, 100$ bp DNA ladder; (A) 1, B. brevis IFO 3331; (A) 2 to 10, B. brevis isolated from food; (B) 1, B. cereus JCM 2152'; (B) 2 to $5, B$. cereus isolated from food; (C) 1, B. circulans JCM 2504 ${ }^{\top}$; (C) 2, B. circulans NBRC 13627; (D) 1, B. coagulans IFO $12583^{\top}$; (D) 2, B. coagulans NBRC 3557; (D) $3, B$. coagulans NBRC 12714, (D) 4, B. coagulans NBRC 3886; (D) 5 to 7, B. coagulans isolated from food; (E) 1, B. firmus JCM 2512'; (E)2, B. firmus NBRC 3330.

isolate (Fig. 3A, Lane 5) showed a similar band pattern with that of the type strain JCM $2505^{\top}$. A RAPD band at about $550 \mathrm{bp}$ was generated from all the $B$. licheniformis strains tested. P. macerans NBRC 3490 produced the same band pattern with that of the type strain $\mathrm{JCM} 2500^{\top}$ (Fig. 3B). P. macerans NBRC 15041 generated bands at both 1700 and 300 bp, which were also generated from the genomic DNA of the type strain and NBRC 3490. The RAPD band patterns generated from 3 different $B$. megaterium strains were different from one another (Fig. 3C). Although all 3 B. polymyxa strains produced RAPD bands at both 500 and $420 \mathrm{bp}$, B. polymyxa NBRC 3020 and 13003 did not generate additional RAPD bands that were generated in the type strain JCM $2507^{\top}$ (Fig. 3D). All 7 B. pumilus strains tested 
(A) B. licheniformis

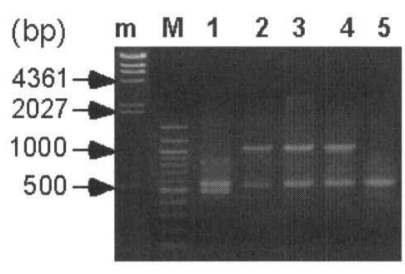

(C) B. megaterium

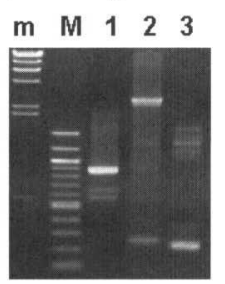

(E) B. pumilus

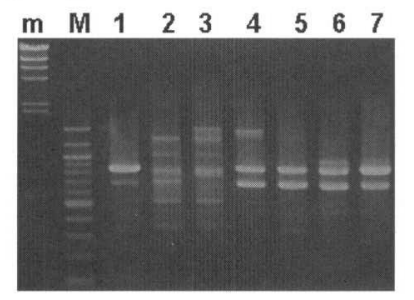

(B) P. macerans

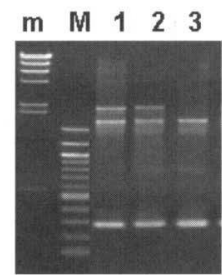

(D) P. polymyxa

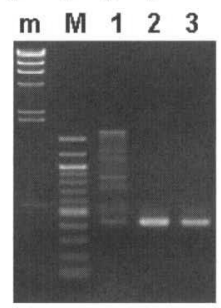

(F) B. sphaericus

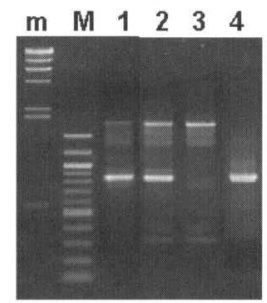

FIG. 3. The DNA band patterns generated with Primer 4 and genomic DNA from some strains of Bacillus and related genera. Lanes: $\mathrm{m}, \lambda$ DNA-Hind III digest; $M, 100$ bp DNA ladder; (A) 1, B. licheniformis JCM 2505'; (A) 2 to 5, B. licheniformis isolated from food; (B) 1, P. macerans JCM $2500^{\top}$; (B) 2, P. macerans NBRC 3490; (B) 3, P. macerans NBRC 15041; (C) 1, B. megaterium JCM 2506 ${ }^{\top}$; (C) 2, B. megaterium NBRC 12068; B. megaterium NBRC 13498; (D) 1, P. polymyxa JCM 2507' ; (D) 2, P. polymyxa NBRC 3020; (D) 3, P. polymyxa NBRC 13003; (E) 1, B. pumilus JCM 2508'; (E) 2 to 7, B. pumilus isolated from food; (F) 1 , B. sphaericus JCM 2502'; (F)2, B. sphaericus NBRC 3525; (F) 3, B. sphaericus NBRC 3527; (F) 4, B. sphaericus isolated from food.

generated RAPD bands at both 700 and 850 bp (Fig. 3E). The 2 B. pumilus isolates (Fig. 3E, Lane 2 and 3) generated several additional bands, which were different from those of the type strain and other isolates. B. sphaericus NBRC 3525 generated the same RAPD band pattern with that of the type strain JCM $2502^{\top}$ though that of strain NBRC 3527 was slightly different from those of the type strain and NBRC 3525 (Fig. 3F). A RAPD band at 850 was clearly detected in the type strain, NBRC 3525 and the isolate 31, but was faint in NBRC 3527. G. stearothermophilus IFO $12550^{\top}$, the type strain, generated a thick band at $750 \mathrm{bp}$, faint ones at 1500, 1100 and 850 (Fig. 1D, Lane 12). G. stearothermophilus isolates showed

\section{(A) G. stearothermophilus}

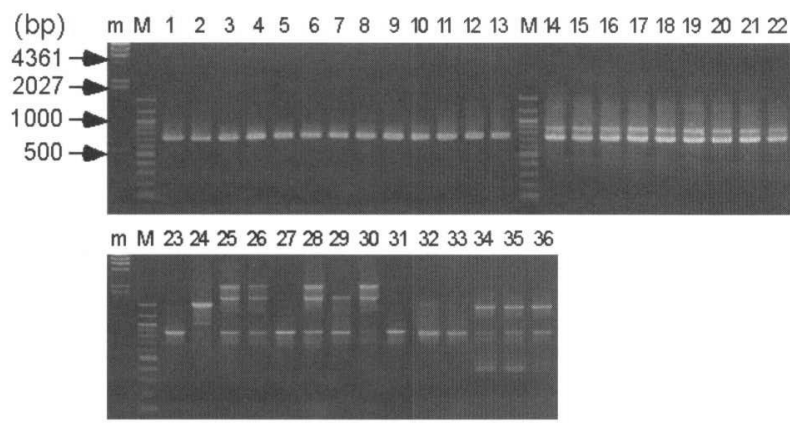

(B) B. subtilis

(C) B. thuringiensis
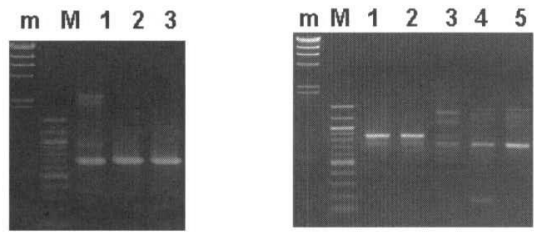

FIG. 4. The DNA band patterns generated with Primer 4 and genomic DNA from some strains of Bacillus and related genera. Lanes: $\mathrm{m}, \lambda$ DNA-Hind III digest; M, 100 bp DNA ladder; (A) 1, G. stearothermophilus IFO 12550'; (A) 2 to 35, G. stearothermophilus isolated from food; (B) 1, B. subtilis JCM $1465^{\top}$; (B) 2 and $3, B$. subtilis isolated from food; (C) 1, B. thuringiensis B; (C) 2, B. thuringiensis sotto; (C) 3, B. thuringiensis IFO 3951; (C) 4, B. thuringiensis IFO 13865; (C) 5, B. thuringiensis IFO 13866.

various RAPD band patterns (Fig. 4A). These bands were estimated to be 2500, 1800, 1500, 1000, 850, 750 and/or $450 \mathrm{bp}$. These strains were classified into 7 groups according to their RAPD band patterns. $B$. subtilis JCM 1465, the type strain, generated a thick RAPD band at $700 \mathrm{bp}$. The same band was also generated in the 2 B. subtilis isolates (Fig. 4B). A thick RAPD band and a faint RAPD band were detected at 850 and $750 \mathrm{bp}$, respectively, in both $B$. thuringiensis sotto and $B$. thuringiensis $B$, but at 750 and $850 \mathrm{bp}$, respectively, in the strains obtained from IFO (Fig. 4C). Although several additional bands were generated from the 3 IFO strains, it seems that $B$. thuringiensis strains commonly generate DNA bands at 850 and 750 bp by RAPD analysis with Primer 4 .

\section{Simple method to identify some Bacillus species and related genera by RAPD analysis combined with morphological observation}

For simple identification of some Bacillus species isolated from food samples by the conventional aerobic plating assay of the sample using Nutrient Agar after heat treatment at $80^{\circ} \mathrm{C}$ for $10 \mathrm{~min}$, the RAPD analysis using Primer 4 combined with morphological observations of colonies, vegetative cells and spores might be effective. Figure 5 shows the proposed 


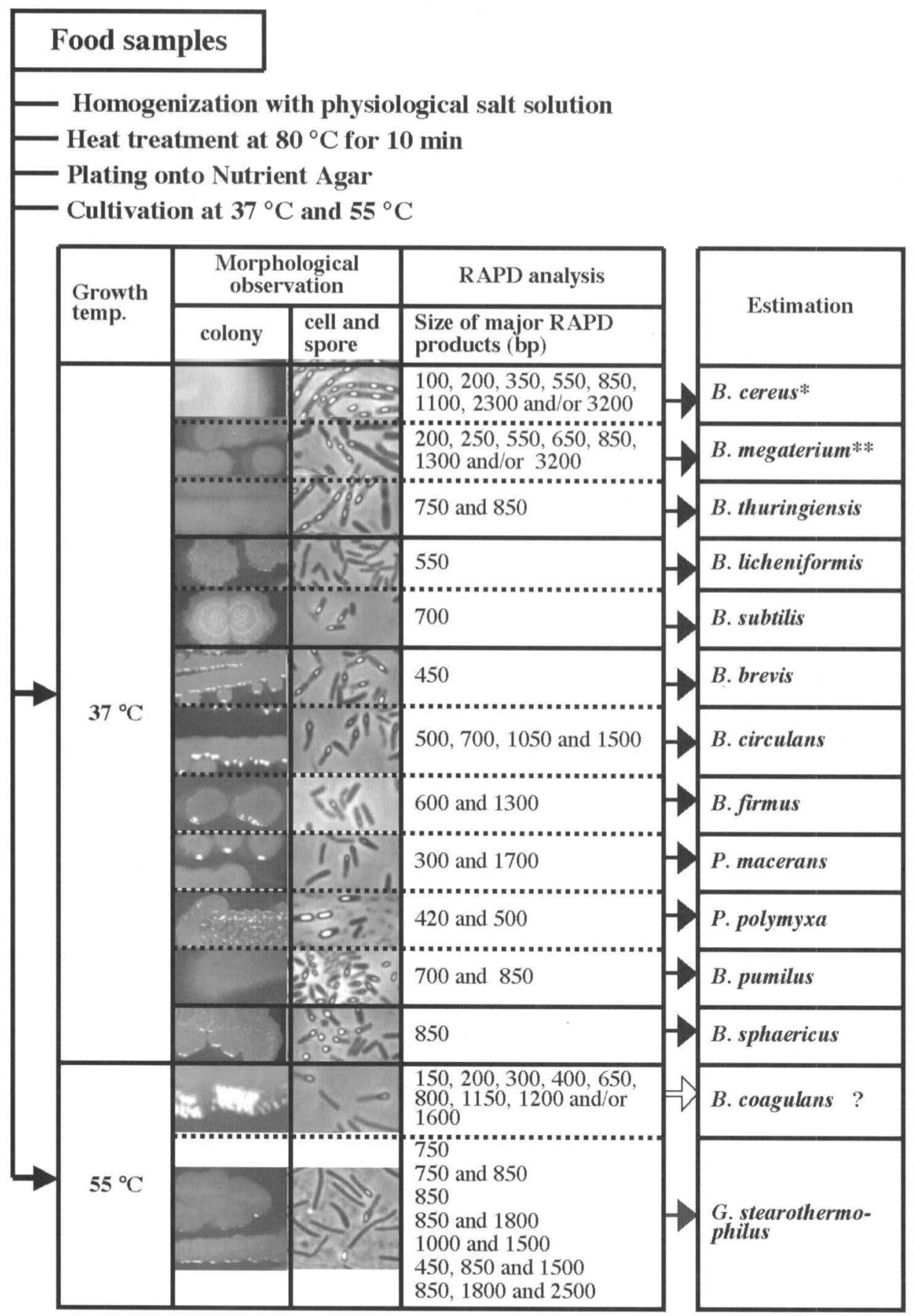

FIG. 5. The proposed simple method to identify some Bacillus species and related genera in food.

* B. cereus could be identified by using selective media.

${ }^{* *} B$. megatrium could be identified with the formation of unstained granules in vegetative cells.

method to identify some Bacillus species and related genera in food. After cultivation at $35^{\circ} \mathrm{C}, B$. subtilis and $B$. licheniformis can be distinguished from other species by their characteristic appearance of colonies: B. subtilis forms irregular, surface-dull and wrinkled colonies; $B$. licheniformis forms rough, surfacedull mounds and lobes consisting of the slime of accumulated colonies. B. sphaericus can be distinguished from other species since it forms spherical spores. B. cereus, B. megaterium and B. thuringiensis are distinguished from other species by the morphological observations of colonies, vegetative cells and spores: their colonies are dull and have a frosted glass appearance, their rod shaped cells tend to 
occur in chains, and ellipsoidal spores are formed at the central of the cells. RAPD analyses of the template DNA prepared from bacterial colonies formed on the Nutrient Agar after cultivation at $35^{\circ} \mathrm{C}$ for 24 to $48 \mathrm{~h}, B$. brevis, $B$. circulans, $B$. firmus, $B$. licheniformis, P. macerans, $P$. polymyxa, B. pumilus, $B$. sphaericus, $B$. subtilis and $B$. thuringiensis might be identified by combination of the present RAPD analysis and morphological observation. B. cereus and $B$. megatrium could be identified respectively by using selective media and with the formation of unstained granules in vegetative cells. For simple identification of G. stearothermophilus, the RAPD analyses of the template DNA prepared from colonies formed on a Nutrient Agar after cultivation at $55^{\circ} \mathrm{C}$ for $48 \mathrm{~h}$ might be effective.

\section{DISCUSSION}

In this paper, we have shown the usefulness of RAPD analysis using commercially available RAPD analysis primers combined with morphological observations of colonies, vegetative cells and spores for the rapid and simple identification of some Bacillus species and related genera. The genus Bacillus includes a variety of phenotypically heterogeneous species exhibiting physiological and metabolic diversity and DNA base composition. In the traditional approaches to identify a strain of the genus Bacillus, complicated physiological tests are required. Several approaches have been proposed to classify Bacillus species, such as those emphasizing morphological and biochemical properties (Smith et al., 1952), spore shape and swelling of the sporangium (Gordon et al., 1973), API test (Berkeley et al., 1984). Joung and Côté (2002) have evaluated ribosomal RNA gene restriction patterns for the classification of Bacillus species and related genera, and indicated that the patterns can be used to reconstruct the phylogeny of the Bacillus species and derived genera. However, their method was complicated and time-consuming for the purpose of rapidly identifying these species, since their method included $4 \mathrm{~h}$ enzyme digestion, $20 \mathrm{~h}$-agarose gel electrophoresis for separation of the digests, Southern hybridization and detection by a radioactive probe.

To reduce the labor and time required for identification, a kit for the identification of Bacillus (Berkley et al., 1984), a RAPD fingerprinting assay (Ronimus et al., 1997) have been reported. Ronimus et al. (1997) have reported that the primer 5'-GGACGACAAG-3' was the most suitable for the identification of Bacillus species among 20 primers tested. They also showed RAPD band patterns generated from the genomic
DNA of isolates from a biofilm sample growing at 72 ${ }^{\circ} \mathrm{C}$ were closely matched with the pattern generated from $G$. stearothermophilus. However, they did not show RAPD band patterns of the other Bacillus species isolated from factories and environment. Soejima et al. (2003) have compared RAPD band patterns of isolates of $B$. licheniformis and $B$. cereus using the same RAPD Analysis primers as those used in this study. They reported that the RAPD Analysis Primers 1,3 and 4 were effective for RAPD analysis of the $B$. licheniformis strains isolated from soybean milk test products. However, they did not refer to the usefulness of these primers for identification of other Bacillus species by RAPD analysis. In our study, different RAPD band patterns were generated from the DNA of 14 different Bacillus species and related genera with Primer 1 or 4 . Although further studies on the other Bacillus species and related genera not tested in this study would be required, our results suggest that the single use of Primer 4 is effective for the simple identification of some Bacillus species and related genera frequently isolated from foods by RAPD analysis.

It has been reported that there are still several difficulties in the identification and characterization of new isolates of thermophilic endospore-forming bacteria of the genus Bacillus and related genera. This is due to the great genotypic and phenotypic variability that characterizes strains belonging to the species of G. stearothermophilus and B. coagulans, the traditional thermophilic aerobic spore-forming bacilli. In this study, RAPD band patterns of some $B$. coagulans strains were similar to that of the type strain and those of the other strains isolated from food were different. In the case of $G$. stearothermophilus strains isolated from food, their RAPD band patterns were classified into 7 groups (Fig. 4A). For identification of $B$. coagulans and $G$. stearothermophilus, the RAPD analyses of the template DNA prepared from colonies formed on a Nutrient Agar after cultivation at $55{ }^{\circ} \mathrm{C}$ for $48 \mathrm{~h}$ might be effective, though further investigations on the other thermophilic endospore-forming bacteria, especially, newly classified Geobacillus species such as $G$. thermocatenulans and $G$. thermoleovorans (Nazina et al., 2001), are required. Among the thermophilic bacteria placed in the classical group of B. stearothermophilus according to their biochemical properties, strains phylogenetically quite distant from the typical $G$. stearothermophilus group should be considered to be other species as mentioned by Nazina et al. (2001).

$B$. cereus and $B$. thuringiensis were indistinguishable by pulsed-field gel electrophoresis and multilocus enzyme electrophoresis (Damgaard, 1995). 
Although differentiation of $B$. cereus and $B$. thuringiensis was also not possible by using oligonucleotide probes directed against the spacer regions between the $16 S$ and 23S rRNA genes (Yamada et al., 1999), the use of selective media such as NGKG agar and MYP agar are effective for the simple identification of $B$. cereus. $B$. cereus are potential food poisoning bacteria that can produce enterotoxins and an emetic toxin causing diarrhea and vomiting, respectively, in humans (Granum and Lund, 1997). Some strains produce toxins and others do not. In our study, B. cereus isolated from food showed different RAPD band patterns with that of the $B$. cereus type strain. Rapid identification of pathogenic $B$. cereus among Bacillus strains isolated from food is very difficult. It seems that for simple identification of pathogenic $B$. cereus by the PCR related methods, the use of a new PCR primer set specific to pathogenic $B$. cereus is required. To increase the accuracy of the rapid and simple identification of Bacillus species and related genera by RAPD analysis using Primer 4 combined with morphological observations of colonies, vegetative cells and spores, RAPD band patterns generated by other primers should be examined for some Bacillus species.

\section{REFERENCES}

Ash, C., Farrow, J. A. E., Wallbanks, S., and Collins, M. D. (1991) Phylogenetic heterogeneity of the genus Bacillus revealed by comparative analysis of small-subunitribosomal RNA sequences. Lett. Appl. Microbiol., 13, 202-206.

Ash, C., Priest, F. G., and Collins, M. D. (1993) Molecular identification of rRNA group 3 bacilli (Ash, Farrow, Wallbanks and Collins) using a PCR probe test. Antonie van Leeuwenhoek, 64, 253-260.

Berkley, R. C. W., Logan, N. A., and Capey, A. G. (1984) Identification on Bacillus species, In "Methods and Microbiology" Vol. 16, (T. Bergan ed.), pp.291-328, Academic Press Inc., London, UK.

Blake, M. R., and Weimer, B. C. (1997) Immunomagnetic detection of Bacillus stearothermophilus spores in food and environmental samples. Appl. Environ. Microbiol., 63, 1643-1646.

Damgaard, P. H. (1995) Diarrhoeal enterotoxin production by strains of Bacillus thuringiensis isolated from commercial Bacillus thuringiensis based insecticides. FEMS Immun. Med. Microbiol., 12, 245-250.

Du Plessis, E. M., and Dicks, L. M. T. (1995) Evaluation of random amplified polymorphic DNA (RAPD)-PCR as a method to differentiate Lactobacillus acidofilus, Lactobacrllus crispatus, Lactobacillus amyolovorus, Lactoibacillus gallinarum, Lactobacillus gasseri, and Lactobacillus johnsonii. Curr. Microbiol., 31, 114-118.

Gordon, R. E., Haynes, W. C., and Pang, C. H. -N. (1973) The Genus Bacillus., Agriculture Handbook no. 427. US government printing office, Washington, DC, USA.

Granum, P. E., and Lund, T. (1997) Bacillus cereus and its food poisoning toxins. FEMS Microbiol. Lett., 157, 223228.

Heyndrickx, M., Lebbe, L., Kersters, K., De Vos, P., Forsyth, G., and Logan, N. A. (1998) Virgibacillus: a new genus to accommodate Bacillus pantothenticus (Proom and Knight 1950). Amended description of Virgibacillus pantothenticus. Int. J. Syst. Bacteriol., 48, 99-106.

Joung, K. B., and Cote, J. C. (2001) Phylogenic analysis of Bacillus thuringiensis serovars based on $16 \mathrm{~S}$ and rRNA gene restriction fragment length polymorphism. J. Appl. Microbiol., 90, 115-122.

Keim, P., Kalif, A., Schupp, J., Hill, K., Travis, S. E., Richmond, K., Adair, D. M., Hugh-Jones, M., Kuske, C. R., and Jackson, P. (1997) Molecular evolution and diversity in Bacillus anthracis as detected by amplified fragment length polymorphism markers. J. Bacteriol., 179, 818-824

Mazurier, S. I., and Werners, K. (1992) Typing of Listeria strains by random amplified polymorphic DNA. Res. Microbiol., 143, 499-505.

Miyamoto, T, Tian, H. Z., Okabe, T., Trevanich, S., Asoh, K., Tomoda, S., Honjoh, K., and Hatano, S. (1998) Application of random amplified polymorphic DNA analysis for detection of Salmonella in foods. J. Food Prot., 61, 785-791.

Nazina, T.N., Tourova, T.P., Poltaraus, A.B., Novikova, E.V., Grigoryan, A..A.., Ivanova, A.E., Lysenko, A.M., Petrunyaka, V.V., Osipov, G.A., Belyaev, S.S., and Ivanov M.V. (2001) Taxonomic study of aerobic thermophilic bacilli: descriptions of Geobacillus subterraneus gen. nov., sp. nov. and Geobacillus uzenensis sp. nov. from petroleum reservoirs and transfer of Bacillus stearothermophilus, Bacillus thermocatenulatus, Bacillus thermoleovorans, Bacillus kaustophilus, Bacillus thermoglucosidasius and Bacillus thermodenitrificans to Geobacillus as the new combinations $G$. stearothermophilus, G. thermocatenulatus, G. thermoleovorans, $G$. kaustophilus, G. thermoglucosidasius and $G$. thermodenitrificans. Int. J. Syst. Evol. Microbiol., 51, 433446.

Poulsen, P., and Jensen, K. F. (1991) Three genes preceding pyrE on the Escherichia coli chromosome are essential for survival and normal cell morphology in stationary culture and at high temperature. Res. Microbiol., 142, 283-288.

Ronimus, R. S., Parker, L. E., and Morgan, H. W. (1997) The utilization of RAPD-PCR for identifying thermophilic and methophilic Bacillus species. FEMS Microbiol. Lett., 147, 75-79.

Smith, N. R., Gordon, R. E., and Clark, F. E. (1952) Aerobic Spore Forming Bacteria, United States Department of Agriculture Monograph no. 16, US government printing office, Washington, DC, USA.

Soejima, T., Tuyuki, S. Nagao, E., Inoue, U., and Kagi, H. (2003) Identification of Bacillus strains as contaminants in soybean milk by RAPD analysis and Southern blotting with 23S rRNA-targeted oligonucleotide probes (Ribotyping), Biocontrol Sci., 8, 55-68.

Turnbull, P. (1997) The role of Bacillus genus in infection. Culture, 18, 5-8.

Wain $\phi$, M., Tindall, B. J., Schumann, P., and Ingvorsen K. 
(1999) Gracilibacillus gen. nov., with description of Gracilibacillus halotolerans gen. nov., sp. nov.; transfer of Bacillus dipsosauri to Gracilibacillus dipsosauri comb. nov., and Bacillus salexigens to the genus Salibacillus gen. nov., as Salibacillus salexigens comb. nov. Int. J. Syst. Bacteriol., 49, 821-831.

Williams, J. G., Kubelik, A. R., Livak, K. J., Rafalski, J. A., and Tingey, S. V. (1990) DNA polymorphisms amplified by arbitrary primers are useful as genetic markers. Nucl. Acids Res., 18, 6531-6535.

Wisotzkey, J. D., Jurtshuk Jr., P., Fox, G. E., Deinhard, G., and Poralla, K. (1992) Comparative sequence analyses on the 16S rRNA (rDNA) of Bacillus acidocaldarius, Bacillus acidoterrestris, and Bacillus cycloheptanicus and proposal for creation of a new genus, Alicyclobacillus gen. nov. Int. J. Syst. Bacteriol., 42, 263-269.

Yamada, S., Ohashi, E., Agata, N., and Venkateswaran, K. (1999) Cloning and nucleotide sequence analysis of gyrB of Bacillus cereus, B. thuringiensis, B. mycoides, and $B$. anthracis and their application to the detection of B. cereus in rice. Appl. Environ. Microbiol., 65, 14831490. 